\title{
Dossiê
}

\begin{tabular}{l} 
REsumo \\
As estatísticas francesas mos- \\
tram que um grande número \\
de maus-tratos dirigidos a \\
crianças de 0 a 3 anos passa \\
despercebido por causa da \\
negação dos pais. Os laços das \\
crianças dessa idade ainda \\
são tão psiquicamente alie- \\
nados a seus pais que elas \\
não conseguem expressar seu \\
próprio sofrimento. Nos pais \\
abusadores, a relembrança \\
de sua própria infância não \\
os deixa diferenciarem-se de \\
suas crianças. Esse laço pais- \\
criança, estruturado apartir da \\
identificaşão projetiva patológi- \\
ca, implica um dispositivo clía \\
nico especialpara o tratamento \\
pais - criança. Esse dispositivo \\
singularpossibilita diferenciar \\
a criança real dessa relação \\
alienante. Isso será ilustrado \\
por meio de um caso clínico. \\
Palavras-chave: Maus- \\
tratos, criança pequena, trata- \\
mento pais - criança. \\
\hline
\end{tabular}

\section{O SOFRIMENTO DA CRIANÇA PEQUENA MALTRATADA E SEUS PAIS}

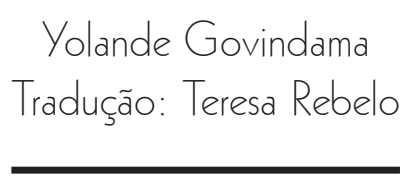

DOI: http://dxdoi.org/10.11606/issn.1981-1624.v20i1p43-58.

Os processos psíquicos da maternidade e paternidade confrontam os pais a uma crise narcísica que pode ser próxima da crise da adolescência. Isso ocorre porque a crise leva cada um dos pais a revisitarem sua infância e suas relações com as imagos parentais interiorizados. Na maternidade é diferente pois a adolescente é forçada a renunciar à sua infância para alcançar o estatuto de adulto. Assim os pais, em particular a mulher, cujo esforço físico mobiliza intensamente o psíquico, têm que mudar de geração de maneira irreversível. Dessa forma, todo nascimento transforma uma geração e mobiliza nos pais não só a pulsão de vida, mas também a pulsão de morte.

- Psicóloga e psicanalista. Professora do Departamento de Psicologia da Universidade de Rouen, Rouen, França. 
A angústia de morte, ativa nos pais, poderá trazer ambivalência parental? Nenhuma ligação direta foi feita até agora pelos autores que tratam a questão dos processos psíquicos da maternidade ou paternidade. Efetivamente, nessa crise narcísica que a futura mãe atravessa para enfrentar sua nova identidade, ela revisita a infância, e até mesmo o infans, pois seu bebê desenvolve características instintivas que evocam certos aspectos animais (BouchardGodard, 1993) e mobiliza as fantasias mais arcaicas da mãe, e também do pai. De fato, o bebê que é para sua mãe um "pequeno estrangeiro interior" desde o começo de sua vida uterina, o será também depois de seu nascimento e, com ele, a mãe vai atravessar um esforço psíquico que a confronta com sua própria alteridade. Isso explica a extrema ambivalência materna, que inclui uma violência impensável (BouchardGodart,1993), e que Bergeret (1984) designa como sendo uma "violência fundamental". Insuficientemente reprimida pela mãe em sua infância, essa violência primitiva favorecerá ou não a passagem do ato à criança, pois ela encarna uma fantasia de infanticida, que seria universal em todas as mães (Bergeret, 1984; Govindama, 2000). Considerando o esforço da maternidade e a fantasia infanticida que acompanharia todo o nascimento, por causa da violência que poderia estar ligada à angústia de morte subjacente, os pais são atravessados pela alegria e também pelo sofrimento ligado à sua história. A depressão pós-parto pode expressar esse sofrimento psíquico. Para os pais maltratantes esse sofrimento é insuportável, pois a criança vem reatualizar a relação que eles viveram com seus próprios pais, trazendolhes, como num espelho, cenas de sua infância. Seus filhos não seriam senão um prolongamento de uma parte do infans dentro de si mesmos. Seriam um duplo narcísico a eliminar, duplo que poderia encarnar a representação da criança do desejo parental, ao qual somos todos confrontados. Criança do desejo parental que terá que ser morta simbolicamente para que o sujeito do desejo aconteça. Mas em um dado contexto, esse assassinato pode tornar-se realidade ou tornar-se um ato falho no maltrato da criança. Não interação mãe-criança (ou pai-criança) está presente um mecae nismo de identificação projetiva patológica. Por isso é difícil tratar, do ponto de vista terapêutico, uma criança pequena sem sua mãe ou pai.

A partir de 1984, construímos um dispositivo em um serviço de ação educacional em ambiente aberto de proteção judiciária da infância, envolvendo a função simbólica da lei como terceiro analítico operante, através da análise dos movimentos de transferências-contratransferêne cias. Apresentaremos aqui a dimensão do problema antes de abordar a dimensão clínica e o dispositivo adaptado a ela. 


\section{Revisão da literatura sobre os maus-tratos na criança pequena de 0-3 anos}

Limitaremos nossa pesquisa à literatura referente às crianças jovens expostas aos maus-tratos físicos e psicológicos, excluindo atentados ao pudor. Os maus-tratos de crianças pequenas e o infanticídio de bebês não é recente. $\mathrm{O}$ infanticídio de bebês na França já preocupava São Vincente de Paulo, que criou um para acolher e possibilitar o abandono anônimo das crianças com o sistema da "torre de abandono".

Durante o século XIX, o infanticídio volta a ser frequente depois que a "torre do abandono" foi suprimida em 1860. Era um modo de regularização dos nascimentos e que também orientou os primeiros estudos médicos, como os de Tardieu (1860), Bernard (1886), e Brouardel (1909). As primeiras leis de proteção à infância apareceram apenas em 1889, e os primeiros estudos sobre crianças pequenas maltratadas começaram na escola pediátrica do Colorado em 1946, com Caffey (1946) sobre a "síndrome do bebê sacudido", Sylverman (1953) sobre a "síndrome das fraturas múltiplas", R.S. Kempe e C.H. Kempe (1978) sobre a "síndrome da criança espancada" e Meadow (1977) sobre a "síndrome de Münchausen" por procuração. Na França esses trabalhos comecaram com Straus e Manciaux (1982) e mostraram a importância de reconhecer a mortalidade de crianças menores de um ano cuja causa são acidentes. Rouyer (1993) evidencia os fatores que provocam os maus-tratos, chamados por ele de "natureza inconsciente do desejo de bebê", como a diferença entre o bebê real e o bebê imaginário, assim como o contexto do nascimento (gêmeos, deficiências, bebês que nascem após luto etc.), independentemente da personalidade dos pais. As estatísticas do ODAS de 2005 (Observatoire Décentralisé de l'Action Sociale) mostram aumento dos maus-tratos psicológicos profundamente negligentes. O SNATED (Service National d'Accueil Téléphonique de l'Enfance en Danger) nota que em 2006 essas negligências estavam relacionadas principalmente com crianças de 0-3 anos. O ONED (Observatoire National de l'Enfance en Danger - 2005-2008) confirma esse aumento de maus-tratos. Os estudos feitos por Becmeur, Danion-Grilliat, Messer, Ludes e Raul (2006-2007) salientam a frequência de fraturas em crianças com menos de 3 anos e a mortalidade de crianças com menos de 3 anos cuja causa é sufocamento e envenenamento, em todos os meios sociais. Mas, segundo esses autores, o objetivo dos 
pais que maltratam não é a morte da criança, mas o de serem reconhecidos eles mesmos como sujeitos sofredores. Nesse casos, poderíamos considea rar que o ato de maus-tratos, sem que a morte esteja presente, seria um ato falho no teatro judiciário para que os pais abusadores tornem-se sujeitos?

A partir de 2008, Tursz, Crost, Gerbouin-Rérolle e Beauté (2008) chamam a atenção dos poderes públicos sobre mortes suspeitas de bebês como sendo consequências de acidentes domésticos, mortes frequentemente aceitas pelos profissionais hospitalares que se deixam contaminar pelo diagnóstico dos pais. E Laurent-Vanier (2012) lamenta a extensão do fenômeno do "bebê sacudido" aceito como sendo "vítima de queda", que nem sempre é acomı panhado de negação da gravidez. Diferentes estudos (Mireau, 2005; Tursz et al., 2008; Tursz \& Cook, 2010; Tursz, 2010, 2011, 2014) confirmam essa afirmação, e a partir de 2014 tornou-se uma causa nacional. Por que o fantasma do infanticídio torna-se uma realidade e está presente na França em todos os meios sociais? O contato com estudos internacionais mostra que os maus-tratos de crianças não restringe-se à França, mas está presente em diferentes soe ciedades, como nos Estados Unidos (Herman-Giddens et al, 2003), no Brasil (Mendlowicz, M. V., Rappaport, M. H., Mecler, K., Golshan, S., \& Moares, T. M., 1998) e na Finlândia (Putkonen et al, 2007). Leventhal 
et al (2007) notam a frequência do "bebê sacudido" e de fraturas múltiplas em bebês, mas salientam que "sacudir o bebê" menino é feito por homens (pai ou padrasto). A síndrome de Münchausen está mais presente nos países ocidentais (Vinville-Loeb et al, 2001), enquanto maus-tratos psicológicos são pouco estudados na França do ponto de vista estatístico, ao contrário de outros países (Hildyard \& Wolfe, 2002).

Se nem o fator social e saúde mental explicam esse fenômeno, que sentido dar-lhe na nossa sociedade pós-moderna? Essa é a razão pela qual o que está em causa na maternidade e paternidade pode nos dar uma resposta à questão atual: por que o fantasma de infanticídio torna-se realidade?

\section{Sofrimento dos pais e falha no recalque da violência fundamental: um laço mórbido entre pais e a criança}

Os processos psíquicos que se executam durante a maternidade favorecem a regressão emocional e psíquica da mãe, o que Winnicott (1956/1969) designou como "a loucura materna". Esse encontro intersubjetivo entre mãe-criança do domínio do arcaico é mediatizado pela cultura, que ordena a natureza, como demonstrado por Lévi-Strauss. Mas segundo Bergeret (1984), a violência primitiva da mãe, reativada durante a gravidez e que inclui uma fantasia infanticida, deve ser recalcada após o parto. Se esse recalcamento foi defeituoso durante a infância da mãe, essa reativação pode favorecer a passagem ao ato dessa fantasia? Bouchard-Godard (1993) explica o aparecimento de uma violência inconcebível durante a gravidez e maternidade, através da parte animal da criança que a ativa, e também através do caráter "estranho" in utero da criança que testa a alteridade da mãe. Descrita por esses dois autores, essa violência seria ligada à angústia de morte mobilizada durante a maternidade e paternidade?

Tornar-se pai ou mãe é ceder seu lugar de criança à sua criança através de uma operação mental que Legendre (1985) designa como uma "permutação simbólica", que permite a instalação da diferença de gerações. O objeto universal de transmissão torna-se a "genealogia simbólica", estabelecendo uma continuação de antepassados, incluindo o mito fundador de toda civilização no sentido totêmico 
freudiano, garantia dos tabus fundamentais da humanidade (tabu de assassinato e incesto). Guyotat (1980) acompanha essa permutação simbólica da organização de filiações (filiação biológica e jurídica, o que envolve o cultural e o simbólico em referência à genealogia e ao subjetivo), onde todos os pais são colocados em um lugar de futuro antepassado, e assim submetidos à sua condição humana, à sua mortalidade.

Mas o que lhes permitem administrar suas angústias de morte é a ilusão de imortalidade através de sua descendência, como como assinala Freud (1915/1982). Nossa própria morte nos é irrepresene tável em nosso inconsciente, enquanto que religiões, incluindo as animistas, deram ilusão de imortalidade a todo ser humano através da fé, da imortalidade da alma ou do espírito (Govindama, Y., \& Payet-Lauret, J., 2011). Mas os maus-tratos das crianças cobrem um ato falho que tem por objetivo matar, através da criança real, a criança do desejo dos pais.

\section{Estudo clínico e dispositivo de tratamento}

A partir de 1980, diante de forte resistência dos pais quando confrontados por juízes de menores por atos de maus-tratos e resistência a colaborarem com o dispositivo de tratamento, juntamente com equipe educacional e profissionais clínicos, desenvolvemos um dispositivo de ajuda inspirada nos de Fraiberg nos E.U.A. para famílias em situção precária e relutantes a qualquer forma de assistência. Para isso, levamos em conta a especificidade do enquadrameto judiciário que é uma "assistência obrigatória", com representações sociais negativas, representações essas que os próprios trabalhadores sociais veiculam. A lei só pode ser o Estado repressivo, moralizador, e especialmente um superego sádico que acaba com o desejo do sujeito, mobilizando assim uma pré-transferência arcaica, persecutória, representando a imago materna. Assim sendo, a lei não pode representar uma função de um terceiro, de simbolizaçao da função paterna. O papel do juiz e sua maneira de interpretar as leis é importante. Ele garante interesses da filiação, mas não faz a lei. O que foi demonstrado pelos magistrados que estudaram a questão por uma perspectiva psicanalítica (Garapon, 1997; Garapon e Salas, 1997). Os trabalhadores sociais (ou clínicos) confrontados com a lei ocasionalmente têm tendência 
a projetar no magistrado a imagem de poder persecutório, confirmando assim a representação que os pais têm do juiz, em uma clivagem que só pode alimentar a clivagem interna dos pais. $\mathrm{O}$ que está relacionado ao que o assistente social mantém com suas próprias imagos parentais (superego parental) e que contamina o dispositivo. Esse dispositivo, reconhecido pela sua eficiência pelas entidades de tutela (saúde e justiça) que credenciaram o serviço com um estatuto específico, foi criado com a colaboração de juízes de menores de Paris.

Esse dispositivo consiste em uma integração entre um assistente social, representante da realidade sócio-educacional e de um clínico, representante da realidade psíquica, em uma aliança terapêutica com o juiz que intervém para receber os pais e a criança que sofre. $\mathrm{O}$ juiz não apenas tem que significar a proibição de violentar a criança (os tabus fundamentais), como também que a passagem ao ato dos pais é a expressão de um sofrimento ou um pedido de ajuda. Um trabalho pode começar a domićlio com todos os participantes, para trazer ao conhecimento o pedido de ajuda. A ação socioeducativa se inscreve em uma aproximação com senso através da escuta da demanda consciente e inconsciente do sujeito pelo clínico. Isso é feito sem infantilizar os pais. Além disso, o sofrimento dos pais se expressa frequentemente através da fala da criança ou na realidade diária na qual o sofrimento está presente.

Assim, é importante acompanhar a escuta de uma observação meticulosa. Efetivamente, é pelo mecanismo de identificação projei tiva patológica que os pais expressam sua história. Pôr em palavras esse sofrimento, traumas da vida real, permite separar gradualmente o infans parental do da criança Acompanhados no reconhecimento das necessidades da criança, os pais descobrem as competências reais dela enquanto sujeito de sua própria história, percepção que não existia anteriormente. $\mathrm{O}$ assistente social acompanha os pais em seu papel com a criança, mas sem agir em seu lugar. Ele faz o mesmo com a criança, trabalhando com o que falta, para desmistificar a mãe que traria tudo (a lei/ideal parental) e trazer para o primeiro plano o desejo do sujeito. Acompanhando os pais, o assistente social respeita seus ritmos de evolução pessoal no plano emocional e psíquico, em um trabalho coerente com o clínico, pois o inconsciente ignora o tempo da realidade. A dimensão da transferência também é levada em consideração para que ele possa administrar essa relação intersubjetiva. O objetivo é reabilitar cada 
um a seu lugar, no que diz respeito às diferenças de gerações, e não consolidar o fracasso da permutação simbólica.

Quando os pais se apropriam da demanda, o tratamento é feito na instituição, solicitando todos os participantes, cada um em sua função, sabendo que eles trabalham em uma ação combinada. Chamamos esse dispositivo de "aliança terapêutica interdisciplinar" (Govindama, 2001; Govindama e Payet-Lauret, 2011; Govindama e Maximy, 2013).

A função simbólica da lei é próxima à cultura no sentido dado por Mauss e Lévi-Strauss, pois toda lei civil ou penal é reflexo da cultura à qual ela refere-se. A lei francesa também é assim. Ela é herança do direito canônico da igreja. Além do fato de que o código civil francês indica no artigo 1200 que qualquer assistência educacional a uma criança imigrante e à sua família tem que respeitar "suas convicções filosóficas e religiosas", consolidando a ligação entre direito e cultura em suas funções simbólicas.

É nesse contexto que acompanhamos Lucie e seu filho Jacques.

\section{O nascimento de Jacques e relembrança do trauma do incesto da mãe}

Jacques tinha 3 meses quando foi levado ao juiz de menores pelo centro materno, que o recebia com sua mãe. Quinze dias após seu nascimento, sua mãe teve gestos de maus-tratos para com ele: uma inadequação entre as necessidades do bebê e as respostas maternas. Ela dava pontapés no berço, tinha uma relação adesiva com o bebê, tinha alucinações visuais por meio das quais via o rosto de seu filho transformar-se em animais e tinha paralisia total do braço direito durante o dia. O quadro clínico evocava uma psicose, e a retirada da criança foi pedida ao juiz. Isso tem por objetivo confiá-lo a longo prazo a uma família que recebe crianças com dificuldades familiares.

O juiz pôs o bebê em um berçário à espera de uma reavaliação da relação mãe-bebê pelo nosso serviço e pelo dispositivo, com o objetivo de um acompanhamento terapêutico.

O bebê já tinha 4 meses quando o vimos pela primeira vez com sua mãe. Deparamo-nos com uma jovem de 20 anos, quase uma adolescente, loira e de olhos azuis, com cabelo sujo e rosto triste. Estava vestida com calças largas e uma camiseta grande demais para

50 Estilos clin., São Paulo, v. 20, n. 1, jan./abr. 2015, 43-58. 
ela, que não deixava aparecer nenhum sinal de feminilidade. Lucie sentou-se na extremidade da cadeira, com o olhar virado para a janela. Sua atitude mostrou relutância à nossa ajuda, embora o juiz tenha lhe dito que seu sofrimento seria ouvido nesse dispositivo clínico. Quando pedi seu endereço, ela disseme que estava sem lugar para morar, que estava desempregada e que vivia com uma amiga desde que seu filho foi colocado no berçário. Expliquei para ela minha dupla função: observação de mãe-criança no berçário, relacionado com a equipe da instituição e acompanhamento individual para ela. Lucie replicou-me "eu quero meu filho de volta, ele é a minha razão de viver. Quanto tempo ele vai continuar no berçário?”.

Depois soubemos pelo pessoal do berçário que assim que ela deu a mamadeira ao bebê cochilou com ele, e que também agrediu a equipe do berçário que, então, pediu ao juiz para diminuir seu direito de visita.

Apresentei-a a um assistente social que poderia ajudá-la a encontrar casa e trabalho. Ela reagiu dando uma risada defensiva e dizendo que "o nome dele lembra um burro para mim". Esta associação do homem com o animal remete suas alucinações visuais. A pré-transferência negativa estava fixada e foi a trama de nossas investigações para achar uma ligação com sua história.

Ela evitou encontrar-se com o assistente social, resolvendo seu problema de alojamento sem ajuda. Nós toleramos isto até que pudéssemos entender o sentido. Depois, concordou em ver-me sem dificuldade. Quando tentava entender sua solidão e perguntei-lhe se ela tinha pais, ela respondeu que não tinha ninguém. Lucie já tinha me dado a impressão de ser órfã. Segundo os dados que possuíamos, sabíamos que ela havia saído muito cedo de casa, se envolvido com drogas e vivido sem abrigo. Foi neste contexto, depois de uma overdose fracassadalha, que ela ficou grávida e sentiu o desejo de ficar com o bebê.

O juiz a convoca para ajustar os direitos de visita de Lucie. Eu a vejo novamente em seguida e, aliviada, ela me conta "Foi tudo bem com o juiz, eu não esperava. Você tinha me falado, mas eu tinha medo. Mas eu compreendi. Além disso eu trabalho, eu não irei mais todos os dias, como antes". O juiz, na sua função de intérprete dos interesses da filiação e da diferença entre gerações, a fez entender que o espaço do berçário é o espaço da criança e que ela é a mãe, buscando não manter a regressão 
cochilando com seu bebê. Foi oportunidade para o juiz limitar o prazer dela e a sua relação adesiva com a criança que ela instrumentou e, não sendo cúmplice nessa fusão incestuosa, nem neste maltrato, ele apoiou o estado de sujeito da criança.

Eu a preparo para a observação mãe-bebê no berçário, e ela me responde: "você vai ver, ele é mestiço, o pai dele é negro". A palavra "observação" evoca aqui o olhar intrusivo, fazendo da criança um objeto de atraçãoaversão, um "estrangeiro em casa" que testa a estranheza nela, resíduo do que ela ainda não nos pode dizer, mas que introduz a sua relação com a alteridade. E ela acrescenta "eu não tenho escolha". O efeito restritivo da lei é onipresente.

A equipe do berçário nos descreve um bebê com boa evolução, mas com um certo imobilismo, principalmente quando solicitado. Tal imobilismo, frequente no bebê maltratado, é chat mado de "vigilância gelada" (Girodet, 1993), conhecido como uma defesa para não incomodar os pais e assim proteger-se da violência. É denominae do por Fraiberg de freezing, a partir dos trabalhos de Guedeney, A., Doleans, M. C. e Huot-Marchand, M. (2003), que sublinham a desorganização dos laços no contexto de maus-tratos.

A sessão de observação se faz numa tarde. Nãs ficamos, eu e ela, em uma sala esperando o bebê que é trazido por uma auxiliar. Lucie sequer olha para a auxiliar. Ela arranca o bebê dos braços dela, o beija com certa violência, como se quisesse comê-lo. Ela instala, sentada no tapete, o bebê em seus braços com as pernas estendidas, para dar-lhe a mamadeira. Ela fica de costas para mim, para que eu não possa observá-los. Eu respeito sua posição para não impor meu olhar intrusivo e evitar uma transferência negativa. Depois da mamadeira o bebê adormece, ficando imóvel e não emitindo nenhum som. O bebê relaxa seu corpo, e Lucie diz: "ele é pesado". Ainda atrás dela, penso que a metáfora do peso corresponde à responsabilidade de ser mãe assim tão jovem.

Quando o bebê acorda, ela o põe no tapete para trocar a fralda e me convida para segui-la. Eu aceito. Ela o coloca no tapete, tira sua roupa e fralda. O bebê a olha com medo, de uma maneira estranha. Ela começa a mordiscar o braço do bebê e acelera o ritmo enquanto que o bebê sufoca. O bebê sofre e me sinto cúmplice da cena. $O$ bebê não suporta mais o excesso de agitação, porém não chora, controlando suas emoções. Perante nosso mal-estar e o do bebê intuitivamente, me identifico emprestando-lhe minha voz e dizendo: "mamãe, tenho medo porque ainda não sei se você está me comendo de verdade ou de mentira, ainda sou pequeno demais para entender". Lucie para e recompõe-se. O bebê me olha e eu o digo "falei por você para dizer à sua mamãe o que você estava querendo dizer com gestos". Ele fixa, então, seu olhar no meu.

Como permitir a essa criança pensar como sendo um sujeito se sua 
mãe não supõe que ele o seja, ou não o representa como objeto de projeções? Lucie continua os cuidados com o bebê com gestos mais adaptados. Ela fala com ele pela primeira vez, mas sem olhá-lo, como se fosse um rival entre ela e as auxiliares. Ela lhe diz que está preparando-o e que ele vai com as senhoras; que ela vai deixá-lo (abandoná-lo). Ela inverte as gerações e transforma-o em pai. Mas, através da criança, é a criança dentro dela que fala da sua própria infância e da sua vivência de abandono. Tendo os cuidados terminados, ela verifica a hora, vira-se para mim e diz: "você vai escrever no relatório o que fiz ao meu bebê". Eu respondo que "o sofrimento se sente, mas não é escrito em um relatório". De fato, o relatório deve resumir somente a evolução do sujeito, excetuando casos de passagem para atos graves.

O bebê volta ao berçário com a auxiliar, que Lucie ataca mais uma vez; eu a recordo de nosso encontro individual. Ela chega ao encontro deprimida e mal vestida. Ela refere-se à cena da observação e demonstra medo de ser julgada e de que eu possa pensar que é uma má mãe. Digo que me parece que ela expressou, através da relação com seu filho, que sua infância foi difícil. Ela começa a chorar, sem poder parar. Eu respeito seu silêncio, demonstrando em uma relação de empatia que ela pode ter toda a atenção de que precisa, visto que tem dificuldade em confiar em adultos e no dispositivo. Ela acalma-se e me conta sua história. Filha única por parte da mãe, mas segunda criança de seu pai. Lucie foi criada por uma babá no interior de seu primeiro até o sexto ano. Ela via sua mãe de quinze em quinze dias e sua avó todos os fins de semana. Ela explica isso pelo fato de que chorava muito e impedia sua mãe de dormir que se levantava cedo para trabalhar em uma padaria. Aos seis anos, ela volta a morar com os pais, os quais conhecia muito pouco. $\mathrm{O}$ sentimento de abandono persiste no lar. Sua mãe saía muito cedo para trabalhar e era seu pai que a levava à escola. Ela diz que "era a primeira a chegar e a última a partir". Lucie expressa assim o quão pequeno era o lugar que ocupava na cabeça dos seus pais.

Ela tinha sete anos quando seu pai foi buscá-la na escola com mais quatro amigos. Chegando em casa, seu pai a estupra e incita seus amigos a fazerem o mesmo. Ela diz: "tive medo de morrer com o peso", e acrescenta: "desde esse dia sou paralítica do lado direito, e fiquei mais ainda com o nascimento do meu filho". Assim, o significante "peso" que ela evocou quando seu filho dormia em seus braços, é associado ao peso dos homens sobre ela, que ela 
sentiu do seu lado direito; tornou-se o lugar de mémoria do traumatismo, para lembrá-la de que continua viva. Traumatismo reativado com o nascimento do filho. Os rostos dos homens (filho, assistente social) que ela via como animais fazem lembrá-la de seus agressores. O quadro clínico que ela apresentou após o nascimento de seu flho era pós-traumático com sintomas dissociativos, mas sem que fosse um quadro clínico de psicose. Em nenhum momento do dispositivo ela apresentou sinais clínicos patológicos (confusão mental, delírio ou alucinações).

\section{Discussão}

Lucie é o caso perfeito para dep monstrar o encontro entre o infans da mãe e o infans da criança, em uma ambivalência extrema com violência implícita nas respostas maternas. Lucie é incapaz de atravessar as mur danças impostas pela maternidade. Assistimos a uma interrupção de sua vida interna; o nascimento de seu filho reativou o traumatismo do estupro de sua infância, resultando no choque entre passado e presente, até o ponto de não poder diferenciar seu próprio filho dos agressores, vendo nele um agressor em potencial. Mas o sofrimento, ligado aos abandonos de sua infância e às falhas do seu estatuto de sujeito, foram expressadas através da sua relação com o filho, colocado no lugar de pais que abandonam, mas também de criança que incomoda. $\mathrm{O}$ mecanismo de identificação patológie ca, usado como principal mecanismo de defesa, vai possibilitar-lhe um tipo de fusão com o objeto, fusão que ela procurava nas drogas e no filho (relação adesiva). A falta e a separação tomaram aspectos angustiantes que ela sentia através do dispositivo e da função simbólica da Lei. O que lhe foi possível, pela relação de identificação especular com o outro que falta, foi experimentar a frustração, a separação simbólica através da separaçao de seu filho, possível graças à mediação da relação por um terceiro (juíz, clínico, auxiliar). Com a evolução, a Lei e a auxiliar tornaram-se suportes para sua reconstrução. Mesmo depois que seu filho voltou à sua guarda, quanà do tinha três anos, Lucie continuou precisando apoiar-se na auxiliar como uma figura materna. Ela não pôde reconciliar-se com sua mãe, que nunca a protegeu. A proteção que teve do juíz (transferência paterna) se transa formou em uma dívida simbólica, e ela orientou-se profissionalmente para o Direito.

O tipo de relação que ela tinha com os homens pôde ser trabalhada através de seu filho, para que ela pudesse pensar em fundar uma família. Jacques está na história de sua mãe sem entender o sentido disso tudo. Nas crises que ela atravessa, ele é seu pai narcísico e incestuoso. Graças à ajuda do berçário e à evolução de sua mãe, Jacques pôde sair dos tipos de 
laços alienantes e começar a existir. A medida que sua mãe o permitira investir no berçário, lugar que ela mesmo tinha transferido como imagem de boa mãe, Jacques se liberava em termos psicomotores, emocionais e de linguagem, sem medo da reação de sua mãe ou da reação dos outros adultos. A culpa materna apareceu em um papel de proteção, e não de vítima no lugar de seu filho, o que restabeleceu os laços geneológicos entre a mãe e o filho.

Quanto ao fantasma infanticida, ele estava nas passagens ao ato, incluindo o estupro do qual a mãe foi vitíma. Mas trata-se de um ato falho feito no plano judiciário, onde através do pedido feito à Lei pela mãe, ela estava, na realidade, pedindo um castigo por ser uma má mãe. A necessidade de castigo não estava relacionada ao seu ato, mas sim à criança não gratificante que ela foi para seus pais, que a teriam abandonado porque ela merecia. E é frequente as crianças maltratadas procurarem um castigo para um crime imaginário (Freud, 1916). E se o juiz de menores só tivesse pedido-lhe para ser mãe, somente salientando suas falhas maternas não vendo nela a menina sofredora, o juíz teria confirmado que ela tinha merecido ser castigada pelos seus pais. Na passagem ao ato sobre seu bebê, Lucie tentava matar o bebê do desejo de seus pais: "objeto de gozo e de rejeição".

\section{Conclusão}

Os maus-tratos de crianças, pequenas demais para falarem, são dificilmente conhecidos, como constata a maioria dos estudos epistemológicos; crianças que também são vítimas de infanticídio e de neonaticídio. Nesses casos, o fantasma do infanticídio, parte integrante das mudanças psíquicas que ocorrem na mulher quando grávida, torna-se realidade. E quando ele transforma-se em maustratos, aparece com o valor de ato falho para expressar o fantasma que está ligado a uma mãe que tenta matar o bebê do desejo dos pais de existir. Existe uma falha de representação do bebê in-utero, nem sempre acompanhado de negação da gravidez, defeito que não permite à mãe supor o bebê como sendo um sujeito. $\mathrm{Na}$ mãe, os processos de pensamento encontram-se travados, mas também os processos de subjetivação e de recalcamento da violência primitiva, necessário para que a mãe possa confrontar a realidade do desconhecido que é o bebê, nesse caso representando um estrangeiro que a persegue. 
A violência fundamental, que é o suporte do fantasma do infanticídio, seria implicitamente ligada à angústia de morte mobilizada nos pais, pois encontram-se perturbados na sequência das gerações. Isso criará um laço mórbido entre a criança e seus pais, o que em Lucie era amplificado quando jogava com a morte ao usar drogas. Mas dar a vida a uma criança sustentou seu desejo de viver. A relação confusa que ela criou com o seu filho só podia travar a transmissão genealógica simbólica, sem que os tabus fundamentais estivessem sólidos. A função simbólica da lei estabeleceu-se na relação, em função do posicionamento de todos os participantes na aliança, por meio da falha e do trabalho conjunto, de maneira que fosse possível restabelecer a transmissão genealógica.

THE SUFFERING OF THE YOUNG CHILD MISTREATED AND HIS PARENTS

\begin{abstract}
The french statistics show the extent of the mistreament of children aged from 0 to 3 years that often goes unnoticed due to the denial of the parents, which contaminates them. The link between parents and children of that age still is so physically alienating that they cannot express their own suffering. For the mistreating parents, the reviral of their own childhood experiences cannot allow them to differentiate themselves from their child. This parent-child link, built from the mechanism of projective and pathological identification, implicates on a singular therapeutic device for the treatment parents-child. This singular device allows differentiate the real child from that alienating relation. This will be illustrated through one clinical case.
\end{abstract}

Index terms: mistreatment, young child, treatment parents - child.

EL SUFRIMIENTO DEL NIÑO PEQUEÑO MALTRATADO Y SUS PADRES

\title{
RESUMEN
}

Las estadísticas francesas muestran la importancia de los fenómenos de abuso en niños de 0-3 años que pasan desapercibidos debido a la negación de los padres, negación que los contaminan. Los lazos de los niños de esta edad aún son tan psíquicamente alienados a sus padres que no pueden expresar su propio sufrimiento. En los padres abusadores, el recuerdo de su propia infancia no los permite diferenciarse de sus hijos. Este vinculo padre - niño, estructurado desde la identificación proyectiva patológica, implica en un dispositivo clinico especial para el tratamiento de padres niño. Este dispositivo único permite diferenciar el ninõ real de esta relación alienante. Esto será ilustrado por medio de un caso clínico.

Palabras clave: abuso en niños; niños pequeños; tratamiento padres - niño. 


\section{REFERÊNCIAS}

Bergeret, J. (1984). La violence fondamentale. Paris: França: Bordas.

Bernard, P. (1886). Des attentats à la pudeur sur les petites filles. Paris : Octave Doin.

Bouchard-Godard, A. (1993). Un étranger à demeure. Devenir, 5(2), 43-60.

Becmeur, F., Danion-Grilliat, A., Messer, J., Ludes, B., \& Raul, J.-S. (2006-2007). L'enfant maltraité: aspects cliniques, psychologiques et médico-légaux. Faculté de Médecine de Strasbourg. Estudo de caso.

Brouardel, P. (1909). Les attentats aux mours. Paris: Baillière

Caffey J. (1946). Multiple fractures in the long bones of infants suffering from chronic subdural hematoma. American Journal of Roentgenology, 56, 163-173.

Freud, S. (1982). Quelques types de caractères dégagés par la psychanalyse. In S. Freud, Essais de psychanalyse appliquée (pp. 133136). Paris: França: Gallimard. (Trabalho original publicado em 1915)

Garapon, A. (1997).Garapon, A. (1997). Bien juger: essai sur le rituel judiciaire. Paris: O. Jacob.

Garapon, A., \& Salas, D. (1997). La justice et le mal. Paris: O. Jacob.

Girodet, D. (1993). Eléments cliniques et démarche diagnostique. In P. Strauss, \& M. Manciaux, L'enfant maltraité (pp. 165204). Paris: Fleurus.

Govindama, Y. (2000). Le corps dans le rituel: ethnopsychanalyse du monde hindou réunionnais. Paris: ESF.

Govindama, Y. (2001). Clinique judiciaire et efficacité symbolique. Psychologie clinique, 11, 72-91.

Govindama, Y. (2011). Temps et rites de Passage: naissance enfance culture et religion. [S.I.]: Karthala.

Govindama, Y., \& Payet-Lauret, J. (2011). Une consultation thérapeutique parents-enfant improvisée à domicile à la réunion. Devenir, 23(4), 325-357.
Govindama, Y., Maximy, M. de (2013). Conflit de loyauté et conflit psychique. Une articulation anthropologique, clinique, judiciaire. Enfance et PSY, (56), 46-56.

Guedeney, A., Doleans, M. C., \& HuotMarchand, M. (2003). Le dépistage relationnel précoce en PMI. Archives de Pédiatrie, 10(1), 131-133.

Guyotat, J. (1980). Mort, naissance et fliation: études de psychopathologie sur le lien de filiation. Paris: Masson.

Herman-Giddens M.E., Smith, J.B. Mittal, M., Carlson, M., \& Butts, J.D. (2003). Newborns killed or left to die by a parent: a population-based study. JAMA, 289 (11), 1425-1429. doi: 10.1001/ jama.289.11.1425

Hildyard, K. L., \& Wolfe, D. A. (2002). Child neglect: developmental issues and outcomes. Child Abuse \& Neglect, 26 (6-7), 679-695. doi: 10.1016/ S0145-2134(02)00341-1

Kempe R.S., \& Kempe H. C. (1978). L'enfance torturée. Bruxelas: Mardaga.

Laurent-Vanier, A. (2012). Syndrome du bébé secoué, quoi de nouveau sur le diagnostic du secouement, le mécanisme en jeu et l'aspect judicaire. Archives de pediatrie, 19, 231-234.

Legendre, P. (1985). Linestimable objet de la transmission: etude sur le principe généalogique en Occident. Paris: Fayard.

Leventhal, M. J., Larson, A. I., Abdoo, D., Singaracharlu, S., Takizawa, C., Miller, C., Goodman, R. T., Schwartz, D., Grasso, S., \& Ellingson, K. (2007). Are abusive fractures in young children becoming less common? Changes over 24 years. Child Abuse and Neglect, 31, 311-322.

Meadow R. (1977). Münchausen syndrome by proxy. The hinterland of child abuse. Lancet, 2, 343-345.

Mendlowicz, M. V., Rappaport, M. H., Mecler, K., Golshan, S., \& Moares, T. M. (1998). Case-Control study on the socio-demographic characteristic of 53 neonaticidal mothers. International journal of law and psychiatry, 21, 209-219. 
Mireau, E. (2005). Syndrome du bébé secoué. Disponível em: syndromedubebesecoue. com/wp-content/uploads/2012/04/these-SBS-Mireau-2005.pdf

Observatoire National de l'Action Social - ODAS (2005). L'acte II de la décentralisation: eléménts de débat. Disponível em http://odas.net/IMG/pdf/200502_ LettreODAS_ActeII_Fev05.pdf

Putkonen, H., Collander, J., Weizmann-Henelius, G., and Eronen, M. (2007). Legal outcomes of all suspected neonaticides in Finland 1980-2000. International Journal of Law and Psychiatry, 30 (3), 248-254. doi:10.1016/j.ijlp.2007.03.008

Raimbault, G. (1975). L’enfant et la mort: des enfants malades parlent de la mort. Problèmes de la clinique du deuil. Paris: Privat.

Rouyer, M. (1993). Psychopathologie de la maltraitance. L'enfant maltraité Paris : Fleurus : 205-262.

Silverman F. N. (1953). The roentgen manifestations of unrecognized skeletal trauma in infants. American Journal of Roentgenology, 69 (3):413-427.

Straus, P., \& Manciaux, M. (1982). L'enfant maltraité. Paris: Fleurus.

Tardieu, A. (1860). Êtude medico-legale sur les services et mauvais craintements exercés sur les enfants. Annales d'Hygiène Publique et de Médecine Légale, 13, 361-398.

Tursz, A., Crost, M., Gerbouin-Rérolle, P., \& Beauté, J. (2008). Étude épidémiologique des morts suspectes de nourrissons en france: quelle est la part des homicides? Bulletin Épidémiologique Hebdomadaire, (3-4), 25-28.

Tursz, A., \& Cook, J. M. (2010). A population based survey of neonaticides using judicial data. Archives of Disease in Childhood - Fetal and Neonatal Edition, 96(4), 259-263. doi: 10.1136/adc.2010.192278

Tursz, A. (2010). Les oubliés: enfants maltraités en France. Paris: Seuil.

Tursz, A. (2011). Les morts violentes de nourrissons: trajectoire des auteurs, traitements judiciaires des affaires. Observatoire national de l'enfance en danger.

Tursz, A. (2014). Les infanticides en France: peut-on les repérer, les compter, les prévenir? Archives de Pédiatrie, 21(4), 343-346.

Vinville-Loeb, B., Olivier, N., Lauquin, P., \& Bailly, D. (2001). Le syndrome de Münchhausen par procuration : revue de la littérature. Journal de Pédiatrie et de Puériculture, 14 (2), 97-103. doi:10.1016/S0987-7983(01)80018-9

Winnicott, D. W. (1969). La préoccupation maternelle primaire. In D. W. Winnicott, De la pédiatrie à la psychanalyse (pp.168-174). Paris: Payot. (Trabalho original publicado em 1956)

marie.govindama@univ-rouen.fr 1, Rue Lavoisier 76821 - Mont Saint Aignan - França Aceito em março/2015. 